\section{Troubled Soviet space effort}

\section{London}

ThE Soviet Union's current mission to Mars and its moon Phobos has been effectively halved. After 75 successful radio link-ups, monitoring trajectory parameters and the performance of on-board instruments, the link-up with the Phobos-1 probe scheduled for 2 September "failed to materialize", according to the TASS agency. Phobos-2, however, is working satisfactorily.

The failure seems to have been caused by a programming error when control of the flight was transferred from the regular control centre in the Crimea to one near Moscow. A flight controller, it seems, inserted an erroneous computer program which left the craft unable to receive commands for its solar panels, so that the batteries have become weak.

The Phobos probes were launched in July and will reach the vicinity of Mars early next year. Nineteen other countries are involved in the mission, either providing experiments and hardware, or as trackers. The US National Aeronautical and Space Administration, in particular, is scheduled to take part in a very-longbaseline interferometry tracing experiment, scheduled to start in October, which has now been put at risk. Fortunately, it is Phobos-2, not Phobos-1, that is scheduled to carry out the more spectacular parts of the mission, dropping the long-life autonomous station and the mobile lander - the hopper — which will be landed on the Martian moon, Phobos, and making the close $(50-\mathrm{m})$ flyby and laser beam spectroscopy experiment on the moon's soil.

The suggestion that the failure was due to a programmer's error comes at a time when the shortcomings of the Soviet computer industry are under attack. The chairman of the Supreme Soviet's Science and Technology Commission, Igor Glebov, said in a recent radio interview that although the Soviet Union has 300,000 trained computer programmers, their productivity is low because they do not have the necessary equipment at their disposal.

Vera Rich

- AcCording to the latest calculations from the European Space Agency, the Soviet surveillance satellite Cosmos 1900 will reenter the Earth's atmosphere on 9 October. The satellite carries a nuclear reactor and is likely to shower nuclear debris around its crash site. Where that will be is still unknown: at this stage ESA can predict only that it will be between $65^{\circ} \mathrm{N}$ and $65^{\circ} \mathrm{S}$. If the satellite begins to tumble it will descend more rapidly and could reach the Earth as early as 20 September.

Alun Anderson

Next round in West Germany's biotechnology licensing struggle

\section{Munich}

BIOTECHNOLOGY companies and environmental activists are at odds in West Germany over the licensing of a biotechnology facility in Hannover. New regulations for production facilities using genetically engineered organisms took effect in West Germany on 1 September. But Invitron Corporation, the US company which is building the Hannover facility, received approval for its plans in August, before the new rules took effect.

Opponents of the plant say they will now use every legal means at their disposal to stop construction of the facility. Under the new regulations, included in the Bundesimmissionsschutzgesetz (federal emission protection act), public participation in the licensing procedure would have been required.

A spokesman for the Green party, Ruth Hammerbacher-Richter, objected to the non-public nature of the licensing procedure of Invitron and complained of a "completely insufficient review of the security aspects" of the new facility. She repeated the Greens' much-used argument that using cell cultures to produce pharmaceuticals is dangerous because retroviruses might grow in the cultures and endanger the population. The local Green party has already submitted an official protest against the licence.

More protests are expected in Marburg where Behring, a division of Hoechst, is applying for permission for a facility using genetically engineered mouse cells to produce the anti-anaemia drug erythropoietin. Behring has resubmitted its application to allow for public discussion.

Marburg Green party member Marina Steindor said that her group would raise the aspect of the "social responsibility" of genetically engineered pharmaceuticals at the public hearings. She cited recent studies showing an unexpectedly high antibody response to human insulin produced using genetic engineering techniques.

For Invitron, a company based in St Louis that receives contracts from other companies to produce monoclonal antibodies and pharmaceuticals using cell cultures, the advantages of building a plant in West Germany outweigh the disadvantages so far. Rick Srigley, vice-president of Invitron, cited the strong reputation of the West German pharmaceutical industry and the large number of potential customers in the Hannover area as reasons for moving there. He seemed prepared to try to ride out the storm of protest. "It is up to the government", Srigley said, to support biotechnology in West Germany. If setting up a plant here "doesn't work out", he added, "the consequences will reach a lot further than Invitron".

The Bundestag (parliament) will deliberate later this year a 'gene law' covering the use of genetic engineering in research and industry. Steven Dickman

\title{
Accelerator for art's sake at the Louvre
}

Paris

THE world-famous Louvre art museum in Paris has just received its own Van der Graaf tandem ion accelerator. Although the accelerator would have been less out of place in the ultra-modern science museum at La Villette than underneath the Louvre's noble Carrousel gardens, ion-beam analysis is playing an increasing role in contemporary conservation and art historical research. The Louvre is the first major museum in the world to have its own dedicated accelerator.

Nicknamed AGLAE (Accélerateur Grand Louvre d'Analyse Elémentaire), after one of the three graces, the US-built accelerator and its shielded environment cost FF10 million ( $\$ 1.6$ million), paid for by the Ministry of Culture and Communication. AGLAE will initially be used in proton-induced $\mathrm{X}$-ray emission mode (PIXE) to enable X-ray spectrographic analysis of art objects within the French national collection, but five further modes are available for other analyses.

As the analysis is rapid, non-destructive

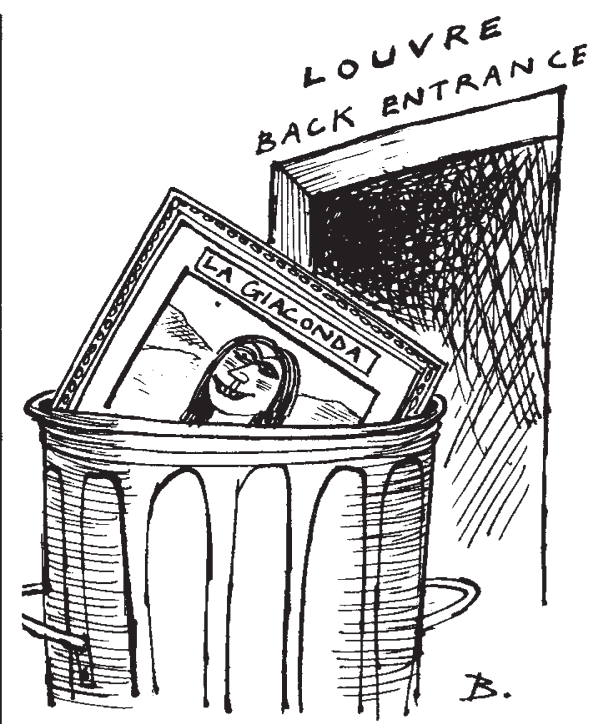

and can be carried out without leaving the tight museum security, even priceless and fragile works can be studied, providing a valuable database for art historians and for the detection of fraud. 